http://jmscr.igmpublication.org/home/

ISSN (e)-2347-176x ISSN (p) 2455-0450

crossref DOI: https://dx.doi.org/10.18535/jmscr/v8i7.40

Journal Of Medical Science And Clinical Research

IGM Publication

An Official Publication of IGM Publication

\title{
Original Research Paper \\ Role of Intravitreal Bevacizumab for the Treatment of Acute Central Serous Chorioretinopathy
}

\author{
Authors \\ Parvez Ahmad Bhat, Arsalan Un Nisa, Shiraz Ahmad Bhat
}

\begin{abstract}
Purpose: To find out the role of intravitreal bevacizumab in the treatment of acute central serous chorioretinopathy (CSC).

Methods: A total of 24 patients of CSC were included in this study and were divided into two groups with 12 patients each. Treatment group received a single intravitreal injection of bevacizumab $(1.25 \mathrm{mg} / 0.05 \mathrm{ml}$; Avastin) and in other group no treatment was given and served as control group. Central maculat thickness (CMT) and best corrected visual acuity (BCVA) were measured at baseline, 6 weeks, 10 weeks, 18 weeks and 24 weeks and were compared between treatment and control groups.

Results: Mean CMT in treatment group at baseline was $507.92 \pm 81.37 \mu$ (range: $380-630 \mu$ ) which improved to $392.17 \pm 65.63 \mu$ ( $p$ value-0.000) at 6 weeks; $344.67 \pm 59.93 \mu$ ( $p$ value-0.000) at 12 weeks; $296.83 \pm 39.93 \mu$ ( $p$ value-0.000) at 18 weeks and $269.75 \pm 30.85 \mu$ ( $p$ value-0.000) at 24 weeks after injection. Baseline BCVA in treatment group was $0.58 \log$ MAR units which improved to $0.44 \log$ MAR ( $p$ value$0.000)$ at 6 weeks; $0.33 \log$ MAR ( $p$ value-0.000) at 12 weeks; $0.26 \log$ MAR ( $p$ value-0.000) at 18 weeks and $0.12 \log$ MAR ( $p$ value-0.000) at 24 weeks after injection. Mean CMT in control group at baseline was $505.92 \pm 123.78 \mu$ (Range: $310-670 \mu$ ) which improved to $398.67 \pm 79.23 \mu$ ( $p$ value-0.000) at 6 weeks; $360.42 \pm 73.37 \mu$ ( $p$ value-0.000) at 12 weeks; $324.67 \pm 56.36 \mu$ ( $p$ value-0.000) at 18 weeks and $293.83 \pm 83 \mu$ ( $p$ value-0.000) at 24 weeks after injection. Mean baseline BCVA in control group was 0.57 log MAR units which improved to $0.47 \log$ MAR ( $p$ value-0.000) at 6 weeks; $0.37 \log$ MAR ( $p$ value-0.000) at 12 weeks; $0.27 \log$ MAR ( $p$ value-0.000) at 18 weeks and $0.175 \log$ MAR ( $p$ value 0.000) at 24 weeks after injection. On comparison of CMT and BCVA at baseline and different follow-ups, between the two groups, no statistically significant difference was seen.

Conclusion: In this study we found that there was no benefit of intravitreal bevacizumab over observation in the management of acute CSC.

Keywords: central serous chorioretinopathy (CSC), best corrected visual acuity (BCVA), central macular thickness (CMT), photodynamic therapy (PDT), optical coherence tomography (OCT), fundus fluorescein angiography (FFA).
\end{abstract}

\section{Introduction}

Central serous chorioretinopathy (CSC) is characterized by serous detachment of the neurosensory retina and frequently causes mild to moderate visual impairment. Fortunately, the disorder is self-limited in the majority of patients, who also regain excellent vision. Although the prognosis is usually favorable, some patients who do not have spontaneous resolution develop pigment epithelial and photoreceptor damage with 
visual impairment. The mechanism for the development of CSC remains unclear. According to one of the hypothesized mechanisms, abnormalities in choroidal perfusion can be causative factors in CSC. Recent indocyanine green angiography in patients with CSC has demonstrated evidence of choroidal lobular ischemia and choroidal venous congestion ${ }^{1}$ and also revealed multiple areas of choroidal vascular hyperpermeability in intermediate stages of the study $^{2}$. The cause of the venous congestion has not been determined, but it may be a response to ischemia and delayed arterial filling or a consequence of outflow obstruction. Choroidal hyperpermeability at foci of subretinal fluorescein leakage is a frequent finding ${ }^{3}$ but choroidal hyperpermeability can also be found without associated fluorescein leakage ${ }^{4}$ suggesting more generalized retinal pigment epithelium (RPE) or choroidal vascular disturbance. Vascular endothelial growth factor (VEGF) is produced by damaged retinal and choroidal cells when abnormal vascular perfusion causes ischemia. By uncoupling endothelial cell-to-cell junctions, VEGF causes vascular permeability and edema ${ }^{5}$ CSC may begin with the changes in choroidal permeability. Therefore bevacizumab may be utilized as a treatment to reduce the choroidal hyperpermeability and reverse the changes seen in CSC. Recently there has been a case report suggesting that intravitreal application of bevacizumab, a humanized monoclonal antibody to VEGF, may have beneficial effects in chronic $\mathrm{CSC}^{6}$. However, we used intravitreal bevacizumab injection for treatment in a few cases of acute CSC. The purpose of the present study is to report the use of intravitreal bevacizumab injection as a treatment for patients with acute CSC.

\section{Methodology}

This is a prospective study conducted at a tertiary care eye facility in northern India. Institutional ethical committee clearance was obtained as well as patient written consent. A total of 24 patients of acute CSC were included in this study. Diagnosis was made on the basis of history, dilated fundus examination, fundus fluorescein angiography and spectral domain- optical coherence tomography. We divided the patients into two groups with 12 patients each. Treatment group received a single intravitreal injection of bevacizumab $(1.25 \mathrm{mg} / 0.05 \mathrm{ml}$; Avastin) and in other group no treatment was given and served as control group. Central macular thickness (CMT) using spectral domain optical coherence tomography and best corrected visual acuity (BCVA) were measured at baseline, 6 weeks, 10 weeks, 18 weeks and 24 weeks and were compared between treatment and control group. All patients were informed about other therapeutic options and the off-label situation of this therapy. Treatment was performed in accordance with the ethical standards of the 1964 Declaration of Helsinki and the informed patient's consent.

\section{Results}

Age range in control group was 28-52 years with mean age of $39.0 \pm 6.86$ years whereas age range in avastin group was $26-49$ years with a mean age of $37.08 \pm 6.45$ years. $(\mathrm{z}=0.67, \mathrm{p}=0.49)$. There were 8 males and 4 females in control group; 7 males and 5 females in avastin group.

In the control group Baseline mean BCVA (table1) was $0.57 \log M A R$ units which improved to 0.47 at 6 weeks; 0.37 at 12 weeks; 0.27 at 18 weeks; and 0.175 at 24 weeks. Mean central macular thickness (CMT) in the control group (table-2) at baseline was $505.92 \pm 123.78 \mu \mathrm{m}$ (range $310-670 \mu \mathrm{m}$ ) which improved to $398.67 \pm 79.23$ at 6 weeks; $360.42 \pm 73.37$ at 12 weeks; $324.67 \pm 56.36$ at 18 weeks; and $293.83 \pm 40.65$ at 24 weeks.

In Avastin group Baseline mean BCVA(table-3) was $0.58 \log$ MAR units which improved to 0.44 at 6 weeks; 0.33 at 12 weeks; 0.26 at 18 weeks; and 0.12 at 24 weeks. Mean central macular thickness (CMT) in the Avastin group (table-4) at baseline was $507.92 \pm 81.37 \mu \mathrm{m}$ (range 380-630 $\mu \mathrm{m}$ ) which improved to $392.17 \pm 65.63$ at 6 weeks; 
$344.67 \pm 59.93$ at 12 weeks; $296.83 \pm 39.93$ at 18 weeks; and $269.75 \pm 30.85$ at 24 weeks.

On comparison of CMT between the two groups (table-5) the p-value at 6,12,18 and 24 weeks came out to be $0.827,0.564,0.163$ and 0.102 respectively which was not statistically significant. On comparison of BCVA between the two groups (table-6) the p-values at 6,12,18 and 24 weeks came out to be $0.770,0.634,0.909$ and 0.235 respectively, which was again not statistically significant.

Table-1: BCVA in control group

\begin{tabular}{|l|c|c|c|}
\hline & Mean BCVA $(\operatorname{logMAR})$ & T-stat & $\mathrm{p}$-value \\
\hline Baseline & 0.57 & & \\
\hline 6 weeks & 0.47 & 4.06 & 0.001 \\
\hline 12 weeks & 0.37 & 5.42 & 0.000 \\
\hline 18 weeks & 0.27 & 10.90 & 0.000 \\
\hline 24 weeks & 0.175 & 11.65 & 0.000 \\
\hline
\end{tabular}

Table-2: CMT in control group.

\begin{tabular}{|l|c|c|c|c|}
\hline & CMT $(\mu \mathrm{m})$ range & Mean CMT $(\mu \mathrm{m})$ & T-stat & p-value \\
\hline Baseline & $310-670$ & $505.92 \pm 123.78$ & & \\
\hline 6 weeks & $270-510$ & $398.67 \pm 79.23$ & 7.15 & 0.000 \\
\hline 12 weeks & $240-475$ & $360.42 \pm 73.37$ & 8.03 & 0.000 \\
\hline 18 weeks & $235-410$ & $324.67 \pm 56.36$ & 8.52 & 0.000 \\
\hline 24 weeks & $230-355$ & $293.83 \pm 40.65$ & 8.42 & 0.000 \\
\hline
\end{tabular}

Table-3: BCVA in Avastin group

\begin{tabular}{|l|c|c|c|}
\hline & Mean BCVA $(\log$ MAR $)$ & T-stat & p-value \\
\hline Baseline & 0.58 & & \\
\hline 6 weeks & 0.44 & 7.34 & 0.000 \\
\hline 12 weeks & 0.33 & 8.66 & 0.000 \\
\hline 18 weeks & 0.26 & 11.66 & 0.000 \\
\hline 24 weeks & 0.12 & 10.01 & 0.000 \\
\hline
\end{tabular}

Table-4: CMT in Avastin group

\begin{tabular}{|l|c|c|c|c|}
\hline & CMT $(\mu \mathrm{m})$ range & Mean CMT $(\mu \mathrm{m})$ & T-stat & p-value \\
\hline Baseline & $380-630$ & $507.92 \pm 81.37$ & & \\
\hline 6 weeks & $290-505$ & $392.17 \pm 65.63$ & 10.88 & 0.000 \\
\hline 12 weeks & $255-465$ & $344.67 \pm 59.93$ & 21.65 & 0.000 \\
\hline 18 weeks & $235-370$ & $296.83 \pm 39.93$ & 12.34 & 0.000 \\
\hline 24 weeks & $232-310$ & $269.75 \pm 30.85$ & 13.58 & 0.000 \\
\hline
\end{tabular}

Table-5: Comparison of BCVA between the two groups

\begin{tabular}{|l|c|c|c|c|}
\hline & $\begin{array}{c}\text { Mean BCVA control } \\
\text { group (logMAR) }\end{array}$ & $\begin{array}{c}\text { Mean BCVA avastin } \\
\text { group (logMAR) }\end{array}$ & z-stat & p-value \\
\hline Baseline & 0.57 & 0.58 & 0.18 & 0.855 \\
\hline 6 weeks & 0.47 & 0.44 & -0.29 & 0.770 \\
\hline 12 weeks & 0.37 & 0.33 & -0.47 & 0.634 \\
\hline 18 weeks & 0.27 & 0.26 & -0.11 & 0.909 \\
\hline 24 weeks & 0.175 & 0.12 & -1.18 & 0.235 \\
\hline
\end{tabular}

Table-6 Comparison of CMT between the two groups

\begin{tabular}{|l|c|c|c|c|}
\hline & $\begin{array}{c}\text { Mean CMT }(\mu \mathrm{m}) \\
\text { control group }\end{array}$ & $\begin{array}{c}\text { Mean CMT }(\mu \mathrm{m}) \\
\text { avastin group }\end{array}$ & z-stat & p-value \\
\hline Baseline & $505.92 \pm 123.78$ & $507.92 \pm 81.37$ & 0.046 & 0.962 \\
\hline 6 weeks & $398.67 \pm 79.23$ & $392.17 \pm 65.63$ & -0.22 & 0.827 \\
\hline 12 weeks & $360.42 \pm 73.37$ & $344.67 \pm 59.93$ & -0.57 & 0.564 \\
\hline 18 weeks & $324.67 \pm 56.36$ & $296.83 \pm 39.93$ & -1.39 & 0.163 \\
\hline 24 weeks & $293.83 \pm 40.65$ & $269.75 \pm 30.85$ & -1.63 & 0.102 \\
\hline
\end{tabular}




\section{Discussion}

CSC is a disease of the retina characterized by serous detachment of the neurosensory retina secondary to one or more focal lesions of the RPE. The high spontaneous remission rate favors conservative management as a first line therapeutic option. But there is some evidence supporting the benefit of early treatment for CSC. A potential benefit for early resolution may be mediated by a lower rate of RPE degeneration in the treated eye $\mathrm{e}^{7}$ which is also warranted because of an uncertain relation between the onset of detachment and that of symptoms ${ }^{8}$ and special occupational demands for binocular visual function.

Although there is no definite evidence about early treatment for CSC, many retinal specialists tend to consider laser photocoagulation, photodynamic therapy (PDT) with verteporfin and some medical treatment as early treatment ${ }^{9}$. Laser photocoagulation and PDT with verteporfin accelerate the resolution of detachment ${ }^{10}$, but they should be used with caution because they can induce permanent damage to the RPE or choriocapillary, severe retinal thermal injury, subretinal choroidal neovascularization, often many years after the primary incident ${ }^{11}$. One experimental study showed that PDT with verteporfin resulted in morphological and functional breakdown of the outer blood-retinal barrier and function of RPE or RPE cells themselves with increasing concentration of verteporfin $^{12}$

In this small case series, we demonstrated that there was resolution of subretinal fluid and improvement in BCVA in both groups over a period of six months. There are number of short case series in past who claim that intravitreal injection of bevacizumab accelerate the resolution of subretinal fluid and improvement of BCVA in CSC patients. But the shortcoming of these few case series is that they have not compared the treatment group with that of the controls. As we know that CSC is a self resolving condition, so we cannot conclude wether the improvement in
BCVA and subretinal fluid in these patients was because of bevacizumab or was it because of natural history of this condition.

To know the actual effect of intravitreal bevacizumab in these patients, it is important to campare it with controls. We compared the two groups in this case series, and found that in both the groups the subretinal fluid resolved and BCVA improved regardless the treatment received or not. When we compared the BCVA and CMT at various follow-ups between the two groups, we did not found any statistically significant difference between the two groups. Based on these findings we found no treatment benefit over conservative management in these patients.

The strength of this study is that we have taken a control group, so that we can actually know if there is any benefit of this treatment modality over observation in these patients. The limitation of this study is that we have taken small sample size, which is not sufficient to make a solid conclusion.

\section{Conclusion}

Based on this case series we found no benefit of intravitreal bevacizumab over observation in acute CSC. In future large sample size with control group is warranted before any conclusion can be made.

\section{References}

1. Hayashi $\mathrm{K}$, Hasegawa $\mathrm{Y}$, Tokoro $\mathrm{T}$ : Indocyanine green angiography of central serous chorioretinopathy. Int Ophthalmol 1986; 9: 37-41

2. Stanga PE, Lim JI, Hamilton P: Indocyaninegreen angiography in chorioretinal diseases: indications and interpretation: an evidence based update. Ophthalmology 2003; 110: 15-21

3. Menchini U, Virgili G, Lanzetta P, Ferrari $\mathrm{E}$ : Indocyanine green angiography in central serous chorioretinopathy. Int Ophthalmol .1997; 21: 57-69.

4. Guyer DR, Yannuzzi LA, Slakter JS, Sorenson JA, Ho A, Orlock D: Digital 
indocyanine green videoangiography of central serous chorioretinopathy.

Arch Ophthalmol 1994; 112: 1057-1062.

5. Weis SM, Cheresh DA:

Pathophysiological consequences of VEGF-induced vascular permeability. Nature 2005; 437: 497-504.

6. Niegel MF, Schrage NF, Christmann S, Degenring RF: Intravitreal bevacizumab for chronic central serous chorioretinopathy (in German). Ophthalmologe 2008; 105: 943-945.

7. Wang MS, Sander B, Larsen M: Retinal atrophy in idiopathic central serous chorioretinopathy. Am J Ophthalmol 2002; 133: 787-793.

8. Wang M, Sander B, la Cour M, Larsen M: Clinical characteristics of subretinal deposits in central serous chorioretinopathy. Acta Ophthalmol Scand 2005; 83: 691-696.

9. Ober MD, Yannuzzi LA, Do DV, et al: Photodynamic therapy for focal retinal pigment epithelial leaks secondary to central serous chorioretinopathy. Ophthalmology 2005; 112: 2088-2094.

10. Burumcek E, Mudun A, Karacorlu S, et al: Laser photocoagulation for persistent central serous retinopathy: results of longterm follow- up. Ophthalmology 1997; 104: $616-622$.

11. Kanyange ML, De Laey JJ: Long-term follow- up of central serous chorioretinopathy (CSCR). Bull Soc Belge Ophtalmol 2002; 284: 39-44.

12. Mennel S, Peter S, Meyer CH, et al: Effect of photodynamic therapy on the function of the outer blood-retinal barrier in an in vitro model. Graefes Arch Clin Exp Ophthalmol 2006; 244: 1015-1021. 